\title{
Potential Risk of Birth Defects after Acitretin Discontinuation
}

\author{
H. Maradit J.-M. Geiger \\ Drug Safety, F. Hoffmann-La Roche Ltd., Basel, Switzerland
}

\section{Key Words \\ Retinoids · Acitretin · Pregnancy · Teratogenesis}

Acitretin (Soriatane ${ }^{\circledR}$, Neotigason ${ }^{\circledR}$ ) is a synthetic retinoid for the treatment of severe forms of psoriasis and disorders of keratinisation. Like other retinoids, acitretin has a teratogenic potential since it affects cellular differentiation and proliferation. With the use of oral isotretinoin (Accu$\operatorname{tane}^{\circledR}$, Roaccutane $\left.{ }^{\circledR}\right)$, malformations involving the central nervous system as well as craniofacial, cardiac and thymic structures have been reported and grouped under the term 'retinoic acid embryopathy' [1] which is however not easily distinguishable from certain congenital syndromes [2]. Though there is no doubt that a risk of birth defect exists when a woman becomes pregnant while using these agents, it is not clear how long she should avoid pregnancy after drug discontinuation [3].

The definition of a post-therapy contraception period is solely based on pharmacokinetic findings. Experience from reported pregnancy outcomes should also be taken into consideration for the evaluation of the teratogenic risk. The most valuable and reliable information is given by prospective cases, i.e. the pregnancy was identified prior to knowledge of the outcome.

We reviewed all world-wide pregnancy data reported to the manufacturer since acitretin became available. Pregnancy information was recorded for both maternal and embryonic/fetal/neonatal outcomes. 'Normal neonate' indi- cates that the mother delivered a baby after the 36th gestational week which looks, measures and functions within normal limits. 'Normal embryo/fetus' indicates that the mother delivered an offspring which appears to have developed normally. Birth defects are categorised according to ICD-10 (WHO, 1992) in malformations and other abnormalities. The term 'malformation' indicates that a structural defect was diagnosed at birth or detected after the examination of an abortus or fetus. Other abnormalities include pregnancy-related, placental, perinatal and neonatal disorders (e.g. abnormal growth, hyperbilirubinaemia, delayed motor skills) not classified as congenital malformations.

As shown in table 1, there were 88 prospective cases out of a total of 123 pregnancy reports. The majority of the pregnancies occurred during the 2-year period after therapy termination. Among the 44 infants born from women exposed to acitretin 0-2 years before conception, there was one abnormality classified as malformation (undescended testicle) and two other abnormalities (one with hypotonia and one with hypocalcaemia and icterus). All other neonates were normal.

We are limited in our ability to study the teratogenic effect of acitretin in humans. The pharmacokinetic findings do not assist much since the threshold blood level for the risk is unknown. Today the recommended post-therapy contraception period is 2 years in almost all countries where acitretin is marketed. This calculation is not based on the elimination half-life of acitretin (2 days) but on that of etretinate (approx. 100 days), since acitretin is potentially esterified in vivo by ethanol into etretinate $[4,5]$.

\section{KARGER \\ Fax +41613061234 \\ E-Mail karger@karger.ch} www.karger.com
1999 S. Karger AG, Basel

1018-8665/99/1981-0003\$17.50/0

Accessible online at: http://BioMedNet.com/karger
Jean-Marie Geiger, MD

F. Hoffmann-La Roche Ltd.

Drug Safety

CH-4070 Basel (Switzerland) 
Table 1. Prospective reports: pregnancy outcome by acitretin exposure time

\begin{tabular}{|c|c|c|c|c|c|}
\hline \multirow[t]{2}{*}{ Pregnancy outcome } & \multirow{2}{*}{$\begin{array}{l}\text { Exposure } \\
\text { during } \\
\text { pregnancy }\end{array}$} & \multicolumn{3}{|c|}{ Before pregnancy } & \multirow[t]{2}{*}{ Total } \\
\hline & & $0-2$ years & $>2$ years & unclear & \\
\hline \multicolumn{6}{|l|}{ Delivery } \\
\hline Normal neonate & - & $41(50)$ & $1(1)$ & $2(5)$ & $44(56)$ \\
\hline With malformations & $1(1)$ & $1(3)$ & $-(3)$ & - & $2(7)$ \\
\hline With other abnormalities & $-(2)$ & $2(2)$ & - & - & $2(4)$ \\
\hline \multicolumn{6}{|l|}{ Therapeutic abortion } \\
\hline Normal embryo/fetus & - & $3(4)$ & - & $-(1)$ & $3(5)$ \\
\hline With malformations & $-(2)$ & $2(3)$ & - & - & $2(5)$ \\
\hline With other abnormalities & $-(1)$ & - & - & - & $-(1)$ \\
\hline No information & $3(3)$ & $20(22)$ & - & $1(2)$ & $24(27)$ \\
\hline \multicolumn{6}{|l|}{ Spontaneous abortion } \\
\hline Normal embryo/fetus & - & $1(1)$ & - & - & $1(1)$ \\
\hline No information & $1(2)$ & $7(12)$ & $1(1)$ & $1(2)$ & $10(17)$ \\
\hline Total & $5(11)$ & $77(97)$ & $2(5)$ & $4(10)$ & $88(123)$ \\
\hline
\end{tabular}

Total reports, prospective and retrospective, are within parentheses.
Prospective follow-up and ascertainment of pregnancy outcome in pregnancy exposures are currently the best available methods even though the cohort size may be limited to draw quantitative conclusions on the risk during specific risk periods. In the current setting, it is crucial that the prescribing physicians and the patients are informed not only about the uncertainty regarding the posttherapy contraception period but also the limitations of research to clarify the question [6].

\section{References}

1 Lammer EJ, Chen DT, Hoar RM, et al: Retinoic acid embryopathy. N Engl J Med 1985;313: 837-841.

2 Coberly S, Lammer E, Alashari M: Retinoic acid embryopathy: Case report and review of literature. Pediatr Pathol Lab Med 1996;16: 823-826.

3 Geiger J-M, Baudin M, Saurat J-H: Teratogenic risk with etretinate and acitretin treatment. Dermatology 1994;189:109-116.
4 Brindley CJ: Overview of recent clinical pharmacokinetic studies with acitretin (Ro 10-1670, etretin). Dermatologica 1989;178: 79-87.

5 Jensen BK, Chaws, CL, Huselton CA: Clinical evidence that acitretin is esterified to etretinate when administered with ethanol. FASEB J 1992;6:A1570.

6 Mitchell AA: Oral retinoids: What should the prescriber know about their teratogenic hazards among women of child-bearing potential? Drug Safety $1992 ; 7: 79-85$. 